\title{
The Application of Project Teaching in The Digital Photography Teaching
}

\author{
Lingling Zhong \\ School of Art Engineering \\ Tianjin Vocatinal Institute \\ Tianjin,China \\ Lingling-zhong@163.com
}

\begin{abstract}
The traditional photography teaching method is difficult to meet the needs of digital photography courses. From the current situation of digital photography teaching, this paper discusses the specific methods of project-teaching in digital photography courses and analyses its effects and advantages. This environment can contribute to improving students' practical abilities and promote the qualities of teaching
\end{abstract}

\section{Keywords- Digital Photography; Project Teaching; Practice}

Over the years, photography has evolved from the simple use of chemical silver halide material into the use of electronic means of physical techniques to capture record images.In recent years, the rapid development of digital technology has influenced on photography greatly, digital photography has become the mainstream of photography. Many colleges and universities has begun to reform in their photography teaching, such as adjusting or reducing the content of traditional film camera photography, and increasing the text of digital photography technology. However, further reform of educational perceptions and teaching methods in digital photography are still needed. Traditional teaching mode, emphasize scientificalness and systematicness of the subject, stressing class-centered, teacher-centered, textbook-centered. This kind of photographic education pays too much attention to the reciting and stating of teaching material, ignoring the teaching in principle, strategy, development and creativity. If students can not understand photographic practice and photographic theory simultaneously very well, it is difficult to adapt to the social requirements which stress practical skills and knowledge innovation. Nowadays, in the courses of college photography, the traditional mode of teaching has not kept up with the requirements of the times, so innovations and reforms shoud be implemented, based on the actual situation.

Digital photography is a course which bring technique, art and practice together, attaching great importance to the students' abilities. The students will not really grasp the skills to master the essentials until they practice by their own hands. However, Project teaching which emphasize practice is a breakthrough in the traditional teaching mode. It focuses on the students, allowing students to explore in real situations independently. In project teaching, students have to accomplish a series of shooting "project" with specific objectives. In this way, it will fully mobilize the enthusiasm of students, enhance students' practical abilities, and effectively improve the quality of digital photography teaching.

\section{CONCEPT OF PROJECT-BASED TEACHING}

The prototype of project teaching was from Cooperative Education in the United States in the 19th century, tended to improve gradually in the late 20th century and became an important theoretical thought of learning. The theory of project teaching as follows: knowledge can be obtained from constructing independently in certain conditions; learning is a process which improves information and knowledge, skills and behaviors, attitudes and idea of values; education is a conscious, systematic, organized continuing exchange activity which can meet the needs of this process. The most significant characteristic of this teaching method is "project is the based line, teacher is the guidance, student is the main part". It is different from the passive teaching mode which is "teacher speaks, and students listen to". It contributes to students' active participation, independent collaboration, exploration and innovation.

\section{THE APPLICATION OF PROJECT-BASED TEACHING IN DIGITAL PHOTOGRAPHY COURSES}

Project is the guidance of applied of project-based teaching in digital photography teaching. Change the traditional teacher-centered mode, so that students can become the main part of teaching activities. It can fundamentally improve students' motivation to learn, and raise the students' abilities of design and practice. The key points of project teaching design as follows:

- An analysis of the project needs. What kind of function can this project realize;

- Task decomposition. What kind of task should this project be decomposed into. And in each task, what kind of knowledge and skills should be covered;

- Pay attention to details. Project pedagogy is expanded in task-driven way.

It is hard to make the knowledge systematically, so summarizing knowledge frequently is essential. Based on specific operation, it is process consists of six steps.

\section{A. Determine the project tasks}

Digital photography belongs to the field of motion skills learning. Students need a lot of direct experience in order to understand the basic principles and skills very well. For this reason, the design of project teaching should start from the easy things. At the beginning of project, the goal of the 
project must be paid attention to. When taking pictures, through analyzing the influence of different parameters of different digital camera on final image, students can understand the basic principles and rules of digital photography. Only in this way, students will learn what they should learn after project is completed. Secondly, we must pay attention to the integrity and operability of the project. From the design, implementation to the accomplishment of project, students should try to practice the learned knowledge as possible as they can and make the habits of normative operations. Using the learned knowledge to solve the real problems, students will have a sense of accomplishment after the completion of the project.

During the implement, it is important to understand the relationship between the project and teaching objectives correctly. Letting the students master the knowledge, skills and abilities is the goal of teaching. It is the starting point and the basis of the project design. When shoot indoor portraits, a portrait shooting can be broken down into several small items which cleverly include the composition, lights, cooperation between shutter and aperture, and the posture of model etc. The teacher uses the main line --- project --- to teach the students, at the same time, students interact with teacher through shooting. Then interactive teaching is completed.

\section{B. Set up project teams}

Group teaching is common mode in project-based teaching methods. In the process of implementation of project, focus on cooperation and competition among students, and try your best to arouse their creative passion. After assigning the task, instead of explaining, teacher should let the students discuss, analyze and ask question, then ask each student to submit photos of different theme. Each group should have students of different level, so students can achieve team collaboration and teamwork.

\section{Project work plan}

According to situation of students' group and the requirements of teaching objectives, teachers will propose the goals, requirements and evaluation criteria of project, and determine the scope and progress that should be finished. Each team should develop project work plan. All the team members will work together to determine the steps and procedures. The plan should include many details, such as theme, time, location, composition, shooting instruements, the ways of performance etc.. In this process, the teacher should conduct students timely. The objective of project is closely related to each member. Every member is a photographer. Teachers should mobilize the enthusiasm of each students. Each member can be delighted to discuss the shooting creativity and technique, and pay attention to themselves and other people's shooting. It will promote the students' digital photography levels greatly.

\section{Organize the implementation of the project}

At this stage, the students will confirm each work and the form of cooperation in this group, then follow the steps and procedures accepted. Each member have his own work, each member collaborates with each other to complete the shooting task. Students will encounter a variety of difficulties, such as the position of the lights, the problems of model's pose, the settings of camera etc. Teachers should not tell the students how to solve the problems faced directly. They should provide students with relevant clues to solve the problem, in order to develop students' self-learning abilities, and to advocate the discussion and exchange between students. Through discussing and complementing with each other, every student's can amend solution of the current problems. In this process, the teachers' guidance is especially important. They should explain the steps of the implementation very well. According to the students' actual situation, remind students timely of what to do first, and what to do next. It will not only help the poor abilities students to finish the task, but also avoid unnecessary detours.

\section{E. Check the results of evaluation}

After processing and handling the pictures, and after communication and discussions with each other, team members submit the completed project. Each team must use the projector to show their results in the class. There must be a representative in each team to elaborate the creative ideas, creative process, use of technical methods, the theme, and the shooting experience in their project. The teacher and the other students may give their opinions on technique of photographic expression. So students can learn more from this. Evaluated by the teacher, project team and student himself, students will know their own advantages in project learning clearly. It would not only motivate students' enthusiasm, but also can make them understand the problems in their work, and then improve future project learning. Finally, each group draws opinions from all sides of the work for making modifications to complete the final product.

\section{F. Exhibition of the achievements and evaluation}

The project works will be shown in a small photography exhibition and reviews can be carried out. Every group can join in this show, and discuss, then evaluate. Evaluation of project-based teaching is also different from that of traditional teaching mode. The evaluation will combine process evaluation and summative evaluation together, specific assessment is: Overall rating = normal performance $(30 \%)+$ team work (30\%) + Final Individual work (40\%). There must be a certain proportion of student's daily performance in this score. And project work of project team accounts for $30 \%$ of the final score so as to enhance team cohesion and sense of honor of the project team. By the teachers' summing up, it is necessary to let the students realize the advantages and disadvantages in their own work in order to improve their photographic creativity and the appreciation of photographic work further. 


\section{THE ADVANTAGE OF PROJECT TEACHING IN DIGITAL PHOTOGRAPHY COURSES}

\section{A. Project teaching will improve the students' interest in learning}

Self-learning is the core of project teaching. It is different from the traditional way of teaching methods which students can only receive the knowledge from teacher's lecture, It changed the structure of teaching. The students showed a strong interest in learning. Students would not sit in a classroom and listen quietly without communication again. The passion of the students has been motivated greatly. Simultaneously students do not have to finish their job after class. They set up their own group, develop project plan, with the teachers' conducting beside them. It will win the active cooperation of the students psychologically, in order to stimulate their participation, and make them learn with interest and ideas, so as to achieve better learning effects.

\section{B. Project teaching bring students independent thinking and problem-solving abilities}

Digital photography teaching use project teaching to break through the limitations of the traditional teaching mode, to improve student's abilities in practice. After finishing the project, each member's techniques of digital photography and artistic expression is greatly enhanced. When encountering problems or difficulties, students are encouraged to obtain information and opportunity of communication on the Internet. This is a good chance for students to exercise independent thinking and to develop individual potential. The project teaching may develop the students' critical thinking and help them to establish a good method to find and solve problem in the process of editing shooting intention, shooting mode, and shooting content.

\section{Project teaching help students integrate into social practice better}

Project teaching help students have a good attitude to improve the techniques in the future social practice. From cooperation with each other, Students mastered the knowledge and skills, simultaneously develop their teamwork and the abilities to adapt to society. Schools can also establish long-term cooperative relationship with photographic company or image Company etc. to carry out a variety of practical activities. The teacher led the students to carry out in real commercial projects, give students access to the actual work environment. This kind of platform that is with producing, learning and researching is the best form of combination between theory and practice. It not only enables students to be close to the actual working conditions, but also let the students understand the situation of photographic industry, meanwhile establish external links. Through participation and completion of the project, the students can acquire knowledge, accumulate experience and increase their abilities, in order to integrate into social practice better.

[1] TANG Nan,The Application of Project teaching in the Portrait Photography Teaching, Journal of Wuxi Institute of Technology, Vo 1.9 ,No.1, February 2010.

[2] Wang Fu,Exploration on the Task-oriented Teaching in Digital Portrait Photography,Journal of Changzhou Vocational College of Information Technology,Vol.10,No.4,August 2011.

[3] Duncum.P,Visual culture.Development,definitions and directions for art education,2001, pp.101-102.

[4] Freedman.k,Teaching visual culture.Curriculum,aesthetics and the social life-of art.New York:Teachers College Press.2004.

[5] reedman.k,Teaching visual culture,Teachers College Press,2003. 